such judgement means. This can only mean an increase in the complexity of the decisions and a lack of easy answers.

\section{The transsexual dilemma}

One contentious area of surgical practice not discussed in the Surgical Colleges' symposium was that of sex change operations. As chance would have it, we are publishing in this same issue three papers on the topic, though none of them from a specifically surgical perspective. The centre of our attention is the experience of the transsexual, and the problems he or she encounters within the present framework of medical practice and legal requirements in Britain. The picture is not a cheerful one. It is understandably difficult for people to appreciate $\stackrel{\mathbb{D}}{\mathrm{a}}_{\mathrm{a}}$ dilemma so far removed from their own experience. Yet since there are now reasonably well establish red medical and psychological criteria for assessing the problems of sexual identity faced by a not incösiderable number of people, through no choice- 0 r fault of their own, it is sad that social attitudes afd outmoded laws continue to provoke unnecess $\overline{\text { ary }}$ suffering. We hope that the descriptions of the difficulties faced by one female-to-male transsexilal (writing pseudonomously) may help to increfse understanding of the human dimensions of this problem.

\section{Reference}

${ }^{1}$ Welbourn, R B (1979) Science and surgery. Austraian and New Zealand fournal of Surgery, 49, 2, I79-1865. 